\title{
PSICO-ONCOLOGIA E GESTALT-TERAPIA: UMA COMUNICAÇÃO POSSÍVEL E NECESSÁRIA
}

\author{
Psycho-Oncology and Gestalt-Therapy: a Possible and Necessary Dialogue
}

Psicooncología y Terapia Gestalt: un Diálogo Posible y Necesario

\author{
RAFAelLa BRito e Silva \\ Carolina Brum Faria Boaventura
}

\begin{abstract}
Resumo: O câncer é uma doença que traz importantes alterações físicas e psicológicas para quem o vivencia, constituindo um estressor ambiental e psicofísico. O adoecer é um processo único e singular do indivíduo, fazendo com que hajam variadas formas de enfrentamento. O presente trabalho propõe uma reflexão sobre as contribuições que a Gestalt-terapia poderá trazer para o acompanhamento psicológico na área da Psico-oncologia. A Gestalt-terapia vem oferecer ao paciente uma possibilidade de obter outra visão de seu adoecimento, que num primeiro momento, parece desintegrador e depois poderá se revelar como uma vivência transformadora. Dessa forma, conhecendo mais a fundo a dinâmica e o significado que a doença tem em sua vida, o paciente poderá tornar-se parte ativa do processo de recuperação, à medida que ele entende como suas emoções e subjetividade estão interferindo direta ou indiretamente neste processo.
\end{abstract}

Palavras-chave: Gestalt-terapia; Câncer; Psico-oncologia.

Abstract: Cancer is a disease which brings about significant physical and psychological change for those who experience it, since it is an environmental and psychophysical stressor. Growing ill is a unique process for each individual and accordingly there are several ways of coping. This work proposes a reflection on the contributions which Gestalt therapy can offer to counselling in the field of Psycho-oncology. Gestalt therapy allows the patient the possibility to take another view on his illness, which at first seems shattering but afterwards may prove to be a transformative experience. Therefore, by knowing more deeply the dynamics and the meaning which the disease has on his life, the patient is able to become an active part of the recovery process, as he understands how emotions and subjectivity interfere directly or indirectly in this process.

Keywords: Gestalt therapy; Cancer; Psycho-oncology.

Resumen: El cáncer es una enfermedad que causa importantes cambios físicos y psicológicos en los que la experimentan, puesto que es un factor de estrés ambiental y psicofísico. Ponerse enfermo es un proceso único e individual, de manera que hay varios modos de hacerle frente. Este trabajo propone una reflexión sobre los aportes que la Terapia Gestalt puede proporcionar a la asesoría en el área de Psicooncología. La Terapia Gestalt ofrece al paciente una oportunidad de obtener otro punto de vista con respecto a su enfermedad, que al principio parece destructiva, pero después puede revelarse una experiencia transformadora. Por consiguiente, conociendo más a fondo la dinámica y el sentido que la enfermedad tiene en su vida, el paciente puede convertirse en parte activa del proceso de recuperación, a medida que comprende cómo las emociones y la subjetividad interfieren directa o indirectamente en ese proceso.

Palabras-clave: Terapia Gestalt; Cáncer; Psicooncología.

\section{Introdução}

Esta é uma pesquisa teórica de cunho qualitativo, com revisão de literatura pautada em livros, artigos científicos da base de dados da Biblioteca Virtual de Saúde na abordagem da Gestalt-terapia e também na área da PsicoOncologia, e destina-se a todo gestalt-terapeuta que tenha interesse em atuar nesta área.

A Oncologia é a ciência que estuda o câncer e como ele se forma, instala-se e progride, assim como as possíveis formas de tratamento. Câncer é uma palavra conhecida desde a Antiguidade, deriva do grego karcinos, que quer dizer "caranguejo". Tem sua origem atribuída ao médico grego Hipócrates (460-340 a.C.) que descre- veu vários tipos de tumores, sendo usada para designar neoplasias com características malignas (Sontag, 2007). O termo abrange mais de cem doenças que podem acometer qualquer parte do corpo humano e se caracteriza pela proliferação abundante de células anárquicas, rebeldes e capazes de produzir um tumor ou uma massa (Ministério da Saúde, 2010a).

O câncer se desenvolve a partir de uma célula do nosso próprio corpo, e, portanto, não é uma doença contagiosa, pois nasce de um problema existente no próprio tecido. É importante salientar que nem todo tumor é câncer, mas todo câncer é tumor. O termo "tumor" se refere apenas a uma massa de tecido, um crescimento anormal em qualquer região do corpo (Ministério da Saúde, 2010a). 
De acordo com a World Health Organization (WHO, 2010b), o câncer é uma das principais causas de mortes da população brasileira, superado apenas pelas doenças cardiovasculares.

Tumores podem ocorrer em qualquer idade, mas a incidência aumenta com o envelhecimento. Porém, apesar do câncer ser mais comum em pessoas idosas, alguns tumores são encontrados em jovens, recém-nascidos e até durante a vida intra-uterina (Younes, 2001). Verificamos o aumento da incidência de câncer nas últimas décadas, e isso se deve a vários fatores: aos efeitos nocivos de exposição a produtos cancerígenos como tabaco, produtos químicos, poluição da atmosfera, radiação; aumento da expectativa de vida e envelhecimento progressivo da população (a maioria dos tumores aparece em pessoas idosas, portanto, viver mais aumenta o número de indivíduos com risco de desenvolver neoplasias); de um melhor diagnóstico (antes, o diagnóstico não era feito, várias pessoas morriam de câncer e atribuíam a morte a outras doenças); além disso, o câncer - nos últimos tempos passou a estar mais "presente" no dia-a-dia, decorrência de uma melhor comunicação da doença ao paciente e à família (hoje como é menos usual esconder o diagnóstico, fica-se sabendo de casos da doença com maior freqüência) (Younes, 2001).

Além do mais, o câncer é causado por muitos fatores externos e internos, que podem estar inter-relacionados. As causas externas relacionam-se ao meio ambiente e hábitos sociais e culturais, e as causas internas, na maioria das vezes, são geneticamente pré-determinadas e também estão ligadas a alterações imunológicas (capacidade do organismo de se defender das agressões externas) (Ministério da Saúde, 2010b).

Em relação aos fatores de risco, estes são encontrados no meio ambiente ou podem ser herdados, de acordo com o Instituto Nacional de Câncer (INCA). A maioria dos casos de câncer está relacionada ao ambiente e estilo de vida (80\%), no qual encontramos grandes fatores como o tabagismo, alcoolismo, radiação solar, hábitos alimentares desregulados, hábitos sexuais inadequados (como falta de higiene, promiscuidade e relação sexual precoce) e fatores ocupacionais, ligados a substâncias químicas no ambiente de trabalho (Ministério da Saúde, 2010).

Há também fatores estressores que causam risco a saúde. No que se refere à questão do estresse, tensão e depressão, Younes (2001) pontua que o estado psicológico do indivíduo influencia o funcionamento do seu corpo, afirmando, porém que o estado emocional de um indivíduo, por si só, não causa câncer. Todavia, estudos recentes apontaram a ação imunossupressora da depressão (Garcia \& cols, 2000; Bottura, 2007). Em outras palavras, a pessoa com depressão tem sistema imunológico de defesa menos eficaz, permitindo que uma célula que por acaso tenha se tornado cancerosa possa se desenvolver com menor oposição da vigilância imunológica.
É recente o interesse pela investigação das relações psicossociais e a incidência, a evolução e a remissão do câncer. No passado, os indivíduos com diagnóstico de câncer eram estudados apenas em termos de quantos sobreviviam e por quanto tempo, estabelecendo-se a relação entre o número de sobreviventes com o tempo de sobrevida e os tipos de tratamentos disponíveis na Oncologia. A Psico-Oncologia traz à tona uma preocupação mais ampla: a qualidade de vida da pessoa com câncer (Gimenes, 2003). A Psico-Oncologia é explicada como uma subespecialidade de Oncologia que procura estudar duas dimensões presentes no diagnóstico de câncer: o impacto do câncer no funcionamento emocional do paciente, de sua família e dos profissionais envolvidos com seu tratamento e o papel das variáveis psicológicas e comportamentais na incidência e na sobrevivência do câncer (Gimenes, 2003).

As intervenções em Psico-Oncologia são definidas como intervenções psicossociais, uma vez que, no caso dos pacientes com câncer, elas não se atêm unicamente aos aspectos psicológicos, mas se propõem a lidar com a dinâmica psicossocial que está sempre presente. A intervenção psicossocial contribui para o tratamento clínico atendendo às necessidades que surgem durante a trajetória do paciente oncológico desde a situação do diagnóstico, ao enfrentamento dos tratamentos, à reabilitação e aos cuidados paliativos, em busca de melhor adaptabilidade do paciente e da família às dificuldades com as quais se deparam (Liberato \& Carvalho, 2008).

Além disso, as intervenções em Psico-Oncologia visam oferecer ao paciente apoio psicossocial e psicoterapêutico, propiciar um espaço seguro para a expressão de seus sentimentos, descobrir meios para a diminuição do estresse, da ansiedade e da depressão, mobilizar recursos para o enfrentamento da doença, aprimorar a comunicação interpessoal, priorizar a qualidade de vida de maneira mais abrangente, criar um campo propício para a busca de novos significados para o processo de viver.

Considerando o manejo psicológico como um elemento de singular importância, com habilidades que contribuam para o alívio do sofrimento humano em prol de melhor qualidade de vida dos indivíduos envolvidos, podemos contar com diversas intervenções psicológicas, que respeitem a fundamentação teórica do profissional, voltado para os pacientes e seus cuidadores (Liberato \& Carvalho, 2008). Nesse contexto, pode-se citar a Gestaltterapia, como uma de várias abordagens que serve de base para o trabalho do profissional, buscando compreender o adoecimento físico e psíquico para se ter a possibilidade de transformação da qualidade de vida dos indivíduos de um modo mais satisfatório.

Além de tornar as pessoas autoconscientes, rompendo as defesas, sentindo e expressando os sentimentos a cada momento, a Gestalt-terapia objetiva a auto-realização (Martín, 2008), resgatando o bom funcionamento do organismo, tanto no aspecto físico, 
como no emocional, pois não há como alterar uma parte sem modificar o todo. A abordagem gestáltica apóia a ideia da existência de grandes diferenças individuais, entre outras, quanto às estratégias de enfrentamento de cada indivíduo com relação aos acontecimentos de sua vida, sejam eles bons ou ruins. Segundo Ribeiro (2007), cada evento da vida é sentido de maneira diferenciada, pois cada um se constitui na medida em que constrói sua existência, que é individual e distinta. É a isso que a gestalt denomina de subjetividade (Antony \& Ribeiro, 2005) o que diferencia e separa um indivíduo dos demais, tornando-o único e singular em sua totalidade. Dessa forma, também ocorre com o processo da doença, tanto com relação à maneira de avaliar a importância e o sentido do adoecer, quanto à maneira de enfrentá-la. Cada paciente vivencia uma série de circunstâncias dentro do contexto de sua história de vida e, para entender o câncer e seu significado para a pessoa que o tem, é preciso situá-lo no contexto de sua biografia.

\section{Concepções de Saúde e Doença na Abordagem Gestáltica}

Na perspectiva gestáltica, saúde e doença não são conceitos estáticos e podem ser entendidos como formas do organismo total tentar dar um sentido peculiar à sua existência, na busca de trocas constantes com o contexto no qual está inserido (Fukumitsu, 2009). Perls (1988) acreditava que a pessoa relaciona-se com e no ambiente, e nas tentativas de adaptação, pode cristalizar seus modos de relação ou flexibilizá-los de formas criativas. Assim, saúde e doença tornam-se processos dinâmicos, possíveis e caracterizados pela interação.

De acordo com a World Health Organization (WHO, 2010b), saúde é um estado completo de bem-estar físico, mental e social e não apenas a ausência de doenças. Esse conceito traz ideias importantes, como a de que ser saudável não significa apenas não adoecer; que a saúde se relaciona primariamente com uma sensação de bemestar, ou seja, não adianta a doença inexistir se o indivíduo se sente doente de alguma forma.

Partindo desse ponto, a Gestalt-terapia tem concepções semelhantes acerca desse assunto. Segundo Barbalho (1998), quando o indivíduo interrompe o contato com ele próprio e com o mundo, sua saúde é prejudicada. Nesse sentido, a interrupção de contato é a suspensão da energia saudável. Nessa abordagem, saúde implica em um reconhecimento da capacidade do indivíduo em manterse em contato com seu contexto podendo, dentro de um processo espontâneo de escolha, optando sobre a melhor forma e o melhor momento de efetuar trocas com o mundo; implica em movimento para a vida, para o contato, para as trocas e para o crescimento, para a awareness. Aqui, awareness é entendida como ter consciência de algo forte e presente, dar-se conta de alguma coisa que ainda não estava presente ou consciente do indivíduo até o momento. É uma forma de experiência que pode ser definida aproximadamente como estar em contato com a própria existência, com aquilo que é (Yontef, 1998). Assim, saúde é a maneira pela qual a pessoa se relaciona com o mundo à sua volta, quando visa o equilíbrio organísmico, a possibilidade de auto-regulação satisfatória com o meio (Rodrigues, 2000).

Cada indivíduo tem uma forma de ser, atuar e estar no mundo, que pode conter limitações, diminuindo suas possibilidades de contato. Mas considerando o ser humano holisticamente, quando se descreve fenomenologicamente as relações que trava com o mundo nesse campo que o cerca do qual ele não está ausente, se percebe que muitas vezes, em tais relações ele se prevê parcialmente, não usando todos os recursos de que dispõe. Logo, tal limitação em viver e entrar em contato com mundo, também poderá se manifestar em seu corpo (Rodrigues, 2000).

Para Brandão (2003), a doença também é vista como a forma física que pode expressar um conteúdo invisível vivido pela pessoa. $\mathrm{O}$ sintoma surge como uma linguagem metafórica, expressando o vivido em seu contexto existencial. Geralmente a doença é vista como algo independente do doente, algo que ataca o organismo, desarranjando seu funcionamento. Contudo, a partir de uma visão holística da pessoa, a doença faz parte e se relaciona não só com o corpo físico e as atividades que interferem diretamente nele como alimentação e esforço físico, mas também com o contexto relacional e com as atitudes do indivíduo consigo mesmo e frente à vida. Assim, o sintoma físico surge como um sinal de alerta, que traz uma intenção e vem carregado de mensagens e significados.

Ribeiro (2007, p. 55) retrata que:

A teoria gestáltica está centrada no conceito de contato, o qual, por sua vez, se faz compreensível a partir da dinamicidade do conceito de formação e destruição de gestalten. Na realidade, porém, não basta formar e destruir gestalten; é importante fechá-las. Só quando se fecha uma Gestalt o processo segue seu curso, e o contato pode ser sentido como excelente porque nada ficou em aberto. Fechar gestalten é o caminho da saúde, pois quanto mais gestalten inacabadas se tem, menos saudável se é, e mais pobre é o contato. De outro lado, fechar gestalten significa encontrar o próprio sentido, a própria fisionomia: é tornar-se senhor de si mesmo.

Para isso, é importante ficar atento a cada necessidade que surge, atendendo-as, cada qual com sua urgência e prioridade. A doença implica em necessidades não satisfeitas, implica na perda da totalidade organísmica (Ribeiro, 2007). Isso significa que quando o organismo não segue seu curso natural de satisfação, seja psicológico ou fisiológico, por meio da homeostase, ele adoece, 
mostrando uma forma - "ajustamento criativo" - de dizer que há algo errado.

Tanto necessidades fisiológicas quanto psicológicas perfazem quaisquer experiências do ser humano, num processo de homeostase. Entretanto, para atingi-la, não há como pensar no indivíduo isoladamente, e sim em constante relação com seu ambiente. A partir desta lógica que surge o conceito de ajustamento criativo onde, a partir desse relacionamento organismo-meio, a pessoa entra em contato, se recria ou se ajusta constantemente às novas situações, de forma saudável criando condições para o seu próprio crescimento e bem-estar (Yontef, 1998). Ainda, é importante ressaltar que nem sempre os processos de ajustamento criativo levam a processos de crescimento saudáveis. Às vezes, a pressão no decorrer da vida é tão forte que a pessoa desenvolve defesas que acabam por limitá-la em sua existência. No entanto, essas defesas devem ser vistas como a melhor resposta que a pessoa pode criar no momento em questão, a melhor forma de encarar tal situação.

A doença pode ser vista como um momento de crise, de transição, como uma oportunidade de mudança, de aprender e desenvolver uma nova forma de vida e de expressar-se de modo mais aberto e direto no mundo. A saúde, como já foi dito anteriormente, não significa ausência da doença, ausência de distúrbios físicos, mas um modo saudável de estar e de se expressar na vida (Brandão, 2003). É a capacidade de “(...) estabelecer articulações eficientes entre a amplitude e as restrições de nosso existir" (Forghieri, 2004, pp. 53).

Assim, saúde é "um equilíbrio apropriado da coordenação de tudo aquilo que somos" (Perls, 1977, p. 20). "Saúde e doença são um processo em contínua alteração, são como figura e fundo em uma totalidade, cuja energia varia na razão em que se alteram os campos onde a realidade, pessoa ou coisa, se manifesta dinamicamente" (Ribeiro \& Alvim, 1997, p. 32).

\section{Gestalt-Terapia e Psico-Oncologia}

O câncer é uma doença que traz importantes alterações físicas e psicológicas para quem o vivencia, constituindo um estressor ambiental e psicofísico. Essa doença expõe o indivíduo a uma rede complexa de condições ao longo das diferentes etapas da doença, exigindo dele respostas adaptativas. O indivíduo com câncer necessita mobilizar recursos psicossociais num esforço adaptativo para lidar com o stress decorrente da enfermidade. A esse processo de mobilização emocional, comportamental e cognitiva, visando a adaptações a situações que mudam a cada etapa da doença, se denomina de enfrentamento (Peçanha, 2008).

As estratégias de enfrentamento em Psico-Oncologia, de acordo com Liberato \& Carvalho (2008) visam principalmente: desenvolver formas mais eficientes de enfren- tamento da doença, promover a expressão de emoções com possibilidade de comunicação intra e interpessoal mais autêntica e fluida, entrar em contato com o sistema de crenças e possibilitar mudanças ao nos estigmas relacionados ao câncer, aprimorar a qualidade de vida dos pacientes e buscar significados para os acontecimentos da vida.

O câncer expõe os pacientes ao estresse físico e emocional de tratamentos dolorosos com efeitos colaterais, na maioria das vezes emocionalmente muito difíceis. Em outras palavras, o câncer expõe o paciente a períodos prolongados de tratamentos farmacológicos agressivos, a submissão a procedimentos médicos frequentemente invasivos e dolorosos, a alterações de comportamento e humor, enfim, ao enfrentamento constante de eventos altamente estressantes (Liberato \& Carvalho, 2008).

Quando o câncer é detectado, a maioria das pessoas reage como a uma notícia catastrófica. Inicialmente, elas têm dificuldade em aceitar o diagnóstico e muitas até pensam que deve haver algum engano nos exames, que não pode acontecer com elas. Quando é extrema e prolongada, essa negação do câncer pode ser perigosa, pois pode impedir que o paciente faça exames necessários ou inicie logo um tratamento que poderá salvar sua vida (Holland \& Lewis, 2000).

Normalmente, à medida que a negação se atenua com o passar dos dias, o indivíduo começa a se sentir impaciente, ansioso e às vezes desamparado. Durante essa fase, muitas pessoas comem e dormem mal e têm problemas de concentração, pois são assombradas por pensamentos repetitivos sobre o diagnóstico e suas implicações. Para Peçanha (2008), infelizmente, é nesse momento que o paciente deve tomar decisões críticas a respeito do seu tratamento, sendo indispensável à presença de um parente ou um amigo para acompanhá-lo.

Quando o tratamento começa, alguns dias após o diagnóstico, a maioria dos pacientes retorna ao seu estado psicológico habitual. Sua maturidade emocional, força de personalidade, coragem e senso de humor determinarão a forma como se adaptam ao câncer em longo prazo (Holland \& Lewis, 2000).

Segundo Brandão (2003), o indivíduo pode participar em seu adoecimento através de comportamentos físicos, emocionais e mentais, como negligenciando a alimentação ou os exercícios físicos, mantendo-se sob muito estresse e sem nenhum relaxamento, preocupando-se em atender aos outros e se esquecendo de si mesmo, limitando por meio de crenças pessoais as suas satisfações na vida.

Isso posto, a doença pode ser vista como uma abertura para novas possibilidades existenciais a partir do confronto com determinados impedimentos. Se o indivíduo não se permite mergulhar no próprio adoecimento e perceber o que ele quer dizer, dificilmente poderá experimentar-se como é esse processo. A exploração de si, o confronto com toda gama de bloqueios e cristaliza- 
ções que participam do contato e da relação sujeito-ambiente deve surgir como um novo processo ativo e delineador de uma conscientização fluida, inteira na totalidade (Remen, 1993).

De acordo com Alvim (2006), a abordagem gestáltica considera o homem e todo organismo vivo interligados com o resto do mundo. Não faz sentido falar do homem isoladamente, pois este vive em determinado meio, que faz parte de sua existência e forma com ele uma totalidade. Não há eventos puramente externos ou internos, mas um organismo e um meio que interagem e têm uma relação de reciprocidade. Nesse contexto, a doença é sempre uma pausa, uma interrupção dos padrões de hábitos nos quais o indivíduo vive, talvez irrefletidamente, durante muitos anos, podendo fazer com que este questione determinados valores, prioridades e maneiras de ser que geralmente são aceitos sem discussão. Ela pode despertar em algumas pessoas a necessidade de compreender mais profundamente quem elas são e o que é importante para elas, levando-as a viverem mais conscientemente e valorizando mais as situações habituais, de acordo com Remen (1993).

É fundamental ressaltar que do outro lado da doença pode não estar a "cura”, entendida como a vitória sobre os sintomas. Porém, é o amadurecimento, a transformação, a transmutação do adoecimento e o consequente contato com os recursos pessoais que faz a grande diferença entre somente lutar contra a doença ou transmutá-la. Logo, a abordagem gestáltica não luta contra tal processo nem busca extirpar os sintomas, mas sim ressignificá-los, visando um funcionamento mais saudável do organismo como um todo. Neste sentido o trabalho gestáltico pretende um resgate da consciência do adoecer aqui-e-agora, considerando sua direta ligação com o ajustamento criativo e com o funcionamento saudável do organismo (Kiyan, 2006).

Se as necessidades psicológicas do paciente também forem acompanhadas, principalmente por ele próprio, provavelmente conseguirá enfrentar o problema do câncer de forma mais eficaz. Holland \& Lewis (2000) afirmam que a psicoterapia, seja em grupo ou individual, tem um impacto sobre a saúde física, porque ao compreender melhor sua forma de interagir consigo e com o mundo, ampliando com isso seu nível de consciência e seu processo de awareness, os pacientes podem encontrar novas alternativas de contato, atendendo melhor às suas necessidades, possibilitando um fluir saudável de formação e fechamento de figuras (ou gestalten).

Imes et al. (2002) relataram que na literatura sobre pacientes crônicos há uma ênfase nos estilos de enfrentamento utilizados pelos mesmos com a finalidade de minimizar o convívio com a doença, mostrando como eles relatam seu funcionamento psicológico. Os autores elucidam as experiências subjetivas corpo/mente que os pacientes obtêm através de sua doença e de que forma eles recebem em sua vida o impacto dessa. Os pacientes foram estudados pelo aspecto do distress (angústia) existencial, experiência corporal, dor, pensamentos, sentimentos e seus esforços de enfrentamento ou de encontrar significados em suas doenças. Esses casos ressaltam a importância de que cada paciente tem sua particularidade e especificidade em sua doença. Por mais semelhante que seja a doença, o modo como o paciente age, sente dor (ou não), as fantasias que apresentam, como interpretam o motivo da doença e o seu contexto em sua vida, é muito singular e característico de cada um.

Como foi visto anteriormente, é pelo contato que o indivíduo se renova, ocorrendo a formação e destruição de novas gestalten. É no contato pleno que se juntam as funções motoras, cognitivas e sensitivas, em um movimento dinâmico, produzindo no indivíduo uma sensação de bem-estar, de escolha, através da consciência emocionada (awareness), de acordo com as noções de Ribeiro (1999). Dessa forma, torna-se fundamental que o paciente seja visto como portador de história pessoal que antecede à própria doença, com suas formas típicas de estabelecer contato consigo e com o mundo.

Ribeiro (2007) observou os mecanismos de defesa e resistência, criando o ciclo do contato como forma de trabalho mais específica em relação ao modo como o indivíduo reage às situações da vida, denominando como "bloqueio de contato" as resistências e defesas, e como "fatores de cura" as possíveis soluções que podem reverter as dificuldades. Segundo o autor, cada ciclo em que uma necessidade é satisfeita, perfaz o contato e o organismo transformado por esse ciclo que se completou se prepara para um novo ciclo. Daí o nome "ciclo do contato", uma vez que é por meio do contato que as necessidades se satisfazem (Ribeiro, 2007).

A idéia do ciclo do contato é perfeitamente coerente com o modo como a natureza procede por meio de ciclos, como os lunares, solares, das estações, só que nesse caso, os ciclos são movimentos orgânicos de procura de satisfação nos mais variados níveis. $\mathrm{O}$ autor examinou ainda a natureza do contato, os fatores que podem facilitá-lo e o seu ciclo de desenvolvimento. Em relação à fenomenologia do contato, ele ressalta que o universo do contato é o universo da totalidade. A psicoterapia, como função do contato, só ocorre quando a totalidade se faz e a mudança tão desejada se dá no tripé: totalidade, consciência e contato (Ribeiro, 2007). Para a Gestalt-terapia, a psicoterapia não necessariamente trabalha com a cura emocional/organísmica, mas sim com mudanças de percepção, o que implica em ressignificar as coisas, as pessoas e a si próprio. Essa mudança é um processo que se dá em três níveis: sensório, motor e cognitivo. Contato é saúde. Saúde é contato em ação. Qualquer interrupção do contato implica na perda da saúde (Ribeiro, 2007).

O Ciclo do Contato contém dois movimentos: o do bloqueio ou de perturbações de fronteira, e o da saúde. Estes dois movimentos se encontram, ora como opostos, ora como complementares, em cada ponto do ciclo. Dada 
a natureza polar do ciclo, cada ponto é, ao mesmo tempo, um diagnóstico, enquanto indica bloqueio ou onde o contato se interrompe (como por exemplo, no mecanismo da proflexão). É também, ao mesmo tempo, um prognóstico, enquanto indica um movimento na direção da saúde (no caso, a interação). Segundo Ribeiro (2007), fator de cura é o processo de experimentação da pessoa, uma sensação de algo novo, gerador de mudança e bem-estar que entrou no universo cognitivo da pessoa e que, por meio da consciência emocionada e da percepção da totalidade, o indivíduo se sente motivado e fortalecido a mudar. Há também os fatores de bloqueio ou perturbações na fronteira de contato ou da saúde.

Contudo, esse mecanismo de bloqueio de contato também tem sua utilidade. Por exemplo, a deflexão é autolimitante, porém muitas vezes é utilizada em momentos onde se deve esquivar de situações demasiadamente dolorosas, de modo que o indivíduo possa se preservar. As defesas são necessárias e benéficas, porém tornamse um problema quando ficam repetitivas e crônicas. $\mathrm{O}$ grande paradoxo das defesas é que elas se instalam para "defender" a integridade do organismo, para manter um equilíbrio (mesmo que ilusório), portanto, é necessário muito cuidado ao se tentar resolver ou quebrar as resistências do paciente (Ivancko, 2006).

Em relação às resistências, Hycner (1995) afirma que existe uma "sabedoria" na resistência, se for conceituada como emergindo naquele ponto em que o indivíduo sente que não tem o suporte interno para lidar com a situação ameaçadora. Nesse ponto, é extremamente sábio proteger-se, juntando os próprios recursos para utilizálos numa ocasião posterior. A resistência protege, mas paralelamente impede a pessoa de crescer.

Assim, o Ciclo do Contato é um prognóstico e nos auxilia no processo de diagnóstico, pois quando se localiza o paciente no ciclo, fica mais fácil tratá-lo. O ciclo fecha uma gestalt, sendo um modelo para se identificar a psicopatologia, visando um processo de mudança do indivíduo. Uma gestalt aberta, entretanto, caracteriza uma energia não totalmente descarregada, que necessita fluir, mas não flui, ficando presa em pontos específicos da história do indivíduo. Portanto, não há a elaboração de uma situação que permanece inacabada, fixada e incompleta (Ribeiro, 2007).

De acordo com Schillings (1997), diversos pacientes oncológicos precisam trabalhar a aceitação da doença e os sentimentos gerados pela mesma como raiva, culpa e decepção, o lidar com a dor decorrente do tratamento, o engajamento necessário e a capacidade de lutar a favor da saúde, a compreensão do adoecer, entre outros. Muitas vezes, a principal tarefa do terapeuta em psicoterapia é ajudar o paciente a desfazer o mal-entendido em relação à sua doença, ou simplesmente escutá-lo, apoiando-o e propiciando momentos para que ele possa colocar para fora suas dúvidas, preocupações, sentimentos e emoções.
É importante tentar reativar nessas pessoas o desejo de viver. Na maioria das vezes, ao se aproximarem desses pacientes, os psicoterapeutas são depositários dos medos, dores, sofrimentos e angústias, que os paralisam frente ao mundo e a si mesmo. Esta é a figura fixa e cristalizada que temos disponível, e é com ela que iremos trabalhar, pois o medo da dor e do sofrimento impedem o crescimento humano através da evitação. $\mathrm{O}$ paciente percebe a sua condição e desvia sua atenção, impedindo-se de dispor de seus próprios recursos de enfrentamento, dificultando a tomada de consciência.

O indivíduo naturalmente poderá repetir seu discurso diversas vezes. Segundo Frazão (1999), as repetições sinalizam cristalizações que impedem a fluidez na formação de gestalten. Repetições muitas vezes podem ser ouvidas como um novo pedido. A questão não é atender ao pedido, e sim ouvi-lo no que concerne à sua função, de tal forma que o pedido expresso possa ser ressignificado e a fluidez do processo de formação e destruição de gestalten seja restaurado. Perls, Hefferline \& Goodman (1997) chamam atenção para o fato de que a compulsão neurótica à repetição é sinal que uma situação inacabada do passado ainda está inacabada no presente, e que é o esforço repetido do organismo para satisfazer uma necessidade que causa a repetição. Nesse contexto é importante que o terapeuta trabalhe no aqui-e-agora, na tentativa de resgatar a atenção do paciente, pois esta atenção possibilitará que as figuras mais importantes emerjam e assim possam ser trabalhadas. Com a integração da atenção e da tomada de consciência ele pode voltar e mobilizar seus recursos de enfrentamento que até então estavam indisponíveis e dar curso ao seu processo em si.

O contato com essas figuras, que aos poucos vai se transformando de um contato doentio para um contato real, possibilita que o paciente se descubra por meio da doença. É nesta fase que a pessoa começa a se apropriar de si, iniciando a sua participação no seu processo, tendo a possibilidade de dar os primeiros passos em relação a dar nova significação a sua doença. Este é um ponto delicado, onde o significado que o paciente dá à sua participação no seu processo pode ser perpassada pela culpa, pelo que ele se permitiu fazer consigo e com sua vida. Possivelmente o terapeuta terá possibilidade de trabalhar com as introjeções que o paciente carrega há muito tempo consigo. Caso essa questão não seja bem trabalhada, o paciente corre o risco de ter mais um introjeto pesando em sua bagagem (Schillings, 1997). Isso significa que se o terapeuta não trabalhar de forma adequada com 0 paciente, pode fazer com que ele introjete a culpa, como ele sendo responsável pela doença, de modo que o sofrimento se torne ainda maior.

O terapeuta deve ter uma percepção acurada e agilidade para poder trabalhar as questões emergenciais que estiverem envolvidas, principalmente pelo fato de que muitas vezes, o terapeuta dispõe de pouquíssimo tempo para começar e terminar um processo terapêutico, uma 
vez que a estadia do paciente no hospital é muitas vezes curta. No momento em que o paciente já não pode mais negar a doença, seja por ele se dar conta que esse recurso de enfrentamento utilizado não é mais suficiente para lidar com a necessidade da sua condição atual, seja porque os sintomas estão mais explícitos (a dor física, a perda de vitalidade ou reações aos tratamentos e etc.), a projeção é uma das defesas usadas na tentativa de amenizar a dor interna (Rossi, 2007).

Saber que tem um câncer já é assustador; no contexto hospitalar todas as coisas externas a si passam a ser nocivas, como o quarto que é muito quente ou frio demais, a comida que é ruim, o travesseiro que é duro, os médicos e enfermeiros que são relapsos e não fazem seu trabalho como deveriam, enfim, todo desconforto interno é projetado no mundo ou no campo que o rodeia. Nesse ponto a terapia tem um papel importante de suporte, dando ao paciente a possibilidade de entrar em contato com a sua dor, e aqui, a dor de ter um câncer se mistura com a dor de não saber como lidar com a situação. Assim, o terapeuta tem a tarefa de acompanhar uma dor que é real, visível e quase palpável.

Dependendo dos recursos de enfrentamento disponíveis e de como o paciente lida com suas dificuldades, a possibilidade de ação pode já estar instalada, precisando então ser mobilizada. Quando isso não ocorre, as fantasias que alicerçam o medo de não conseguir tomam grandes formas e impedem o aparecimento de recursos já existentes. $\mathrm{O}$ paciente experimenta um estado de paralisação, causado muitas vezes por forças em oposição (as polaridades). Numa polaridade está o medo, o não saber o que fazer ou o não suportar a realidade, na outra está o que o mantém vivo, o que lhe dá esperança, sua força para seguir em frente. É importante que sejam trabalhadas essas polaridades, visto que com a identificação e apropriação de suas partes consideradas frágeis e a percepção sua força, o paciente tem a possibilidade de fazer que com essa luta interna (de conflitos) seja dissolvida, dando espaço a recursos para a luta presente e necessária, que é a de viver (Schillings, 1997).

Ainda, o psicoterapeuta poderá utilizar algumas técnicas da Gestalt-terapia. As técnicas de intervenções são muitas vezes erroneamente confundidas com a própria Gestalt-Terapia e para que sejam utilizadas devem ter uma finalidade específica, um motivo para serem usadas e um objetivo a ser almejado. A criatividade do terapeuta e a necessidade do paciente é que delinearão a utilização ou não de uma determinada técnica (Ivancko, 2006).

A “cadeira vazia” é uma técnica bastante utilizada que consiste em orientar o paciente a imaginar e dialogar com a pessoa com quem tenha assuntos para resolver, fazendo com que ela viva os dois lados do conflito, ou seja, presentifique uma situação cujo desfecho e assimilação não foi possível (Ivancko, 2006). Dessa forma, é trabalhada a integração das partes de um todo, projeções, introjeções, confluências, deflexões, retroflexões, enfim, conflitos internos e/ou externos. Essa técnica tem sido ao longo dos anos uma das mais conhecidas da GestaltTerapia. Geralmente era utilizada por Perls em situações de grupo, quando aconteciam os workshops, ocasião em que difundia suas técnicas e teoria para profissionais em formação ou grupos terapêuticos (Kiyan, 2006).

Já a "imaginação" ou "fantasia dirigida” tem o propósito de conduzir o paciente a situações e cenários, reais ou não, cujos conteúdos emergidos serão trabalhados. O terapeuta poderá utilizar a imaginação onde existem componentes reais e concretos, porém cada sujeito irá imaginar a questão em foco, o que pode não ter correspondência com a questão real, mas correspondente à fantasia da questão (Polster \& Polster, 2001). Quatro grandes propósitos podem ser conseguidos com o uso da fantasia dirigida: contato com um acontecimento, sentimento ou característica pessoal que encontra resistência; contato com uma pessoa não disponível ou uma situação inacabada; exploração do desconhecido; e exploração de aspectos novos ou não habituais de si mesmo.

Diante da doença, assim como também nas experiências do dia-a-dia, o indivíduo buscará uma compreensão do processo de seu adoecimento, um sentido para a doença, mesmo que não seja de forma consciente, no que certamente influenciará nas estratégias de enfrentamento por ele utilizadas. Nesse sentido, as variáveis diversas são atribuídas pelo próprio paciente, como mitos, segredos, metáforas. Tudo isso pode interferir na postura de esperança ou desespero por parte tanto dos pacientes quanto dos membros envolvidos (familiares) na visão de Liberato \& Carvalho (2008).

Assim, intervenções que tragam oportunidade de condições melhores para que o paciente enfrente a vida de forma mais eficaz, de maneira que a adesão aos tratamentos bem como a relação consigo se torne mais satisfatória, são de extrema importância para que se consigam melhores resultado quanto ao processo de viver. Enfrentar a vida de forma mais eficiente pode significar o atendimento das necessidades pessoais. É preciso acompanhar os aspectos subjetivos do paciente, com aquele que sofre, a avaliação que ele faz a respeito de suas condições de vida e conhecer as expectativas que nutre, de acordo com a visão que define a expressão do ser humano integral, considerando as áreas físicas, emocional, social e espiritual (Liberato \& Carvalho, 2008). Os autores acrescentam que o acompanhamento psicológico e suas intervenções têm como objetivos evitar que as situações de crise se tornem crônicas, auxiliar na criação de um novo sentido da experiência dolorosa e fazer com que o indivíduo retome seu espaço no mundo, participando da busca do estado de saúde, que implica em conviver com as demandas que o ato de viver envolve.

O câncer é uma doença crônica grave e que muitas vezes se desenvolve silenciosamente, de modo que o indivíduo não se reconhece "a priori" como doente, devido aos sintomas físicos se manifestarem muito tempo de- 
pois. Ele vai pouco a pouco se apossando, invadindo o organismo, fazendo com que este viva uma guerra total, tanto física quanto emocional.

O tratamento acarreta em uma série de mudanças na vida do paciente, como na sua rotina, aspectos fisiológicos, psicossociais, no trabalho, nos papéis familiares e sociais, em suas metas de vida futura. O paciente com câncer enfrenta diversas dificuldades como a luta contra a doença, a adaptação aos tratamentos, problemas emocionais (raiva, depressão, culpa, desespero, medos como os da morte entre outros) e também os físicos (dependendo do grau em que a doença se encontra). Isso tudo se remete ao enfrentamento. $\mathrm{O}$ adoecer é um processo único e singular de cada indivíduo, fazendo com que haja variadas formas de enfrentamento. Não existe um só fator como determinante nem uma estratégia mais eficaz, pois as formas de enfrentamento que os indivíduos escolhem são multifacetadas e estão relacionadas à natureza da doença, dos sintomas, da localização, do estágio, tipo e evolução do tratamento, das possíveis reabilitações, ao nível de auto-estima, relacionamento familiar, educação, padrões sociais em que este atuam, vulnerabilidades da doença e outros fatores.

O acompanhamento psicológico dentro do âmbito hospitalar oncológico ajuda o paciente a situar-se em sua condição atual e, emocionalmente, a passar por todas as fases do tratamento, dando-o suporte para a readaptação e um enfrentamento mais positivo, de forma que possa ajudar no tratamento como um todo.

O paciente não escolhe ter um câncer, mas pode escolher como lidar com isso. Sempre existe a possibilidade de se olhar como vítima da vida e se lamentar constantemente, transformando cada dia num calvário, ou a situação pode ser enfrentada de maneira menos sofrida, percebendo que, apesar dos limites, a vida ainda poderia acontecer.

\section{Considerações Finais}

A partir do exposto neste trabalho, percebe-se que há muito a se fazer para facilitar uma experiência diferente em relação ao adoecimento. Embora a Gestalt-Terapia tenha poucas produções bibliográficas referentes a pessoas com câncer (o que torna de extrema importância mais pesquisas acerca do assunto), acreditamos que a Gestalt abre possibilidades para ressignificar o processo do adoecer, incentivando o auto-suporte de cada paciente, para que cada um deles esteja aware da sua condição e consiga disponibilizar recursos internos para enfrentar a doença. Ao considerar a doença de forma processual, ou seja, um processo vivido pela pessoa como um todo, em sua totalidade dinâmica, que tem sentidos e significados na existência daquele indivíduo em particular, a Gestalt-terapia contribui significativamente para um olhar a respeito das emoções envolvidas na dinâmica do câncer, no qual está relacionado com a história de vida do indivíduo, e conseqüentemente, às suas experiências e emoções vivenciadas como um todo.

É preciso que o indivíduo tenha em mente a idéia de que é fundamental liberar suas emoções, como chorar, gritar, protestar, dizer o que incomoda e o que não gosta, isto é, ser autêntico com os verdadeiros sentimentos. Também é preciso aceitar que a pessoa tenha sentimentos ruins, pelo simples fato de ser humano e de que essas sensações também são importantes para o crescimento individual, pois é no conflito e na diferença é que o homem tem a possibilidade de crescimento. E isso só acontece se a pessoa estiver em sintonia consigo, acompanhando o seu pensar, seu agir, com o seu processo fluido.

É de grande importância contextualizar a doença, pois cada câncer é peculiar. Mesmo quando duas pessoas apresentam semelhantes tipos de câncer, para cada uma delas o câncer tem um significado e uma história própria, bem como sua evolução, piora ou melhora específicas de cada uma. Isso porque a doença não é um fim em si mesmo, ou seja, as coisas isoladas não têm significado, o significado vai existir e vai ser diferente em cada contexto. Da mesma maneira acontece com o câncer, cada um é único, pois cada pessoa é singular.

A Gestalt-terapia vem oferecer ao paciente uma possibilidade de obter outra visão de seu adoecimento, que num primeiro momento, pode parecer desintegrador e que depois se revela como uma vivência transformadora. Dessa forma, conhecendo mais a fundo a sua dinâmica e o significado que a doença tem em sua vida, o paciente poderá tornar-se parte ativa do processo de recuperação, na medida em que ele entende como suas emoções e subjetividade estão interferindo direta ou indiretamente neste processo. Por isso, para a Gestalt-terapia, muito mais importante do que escutar o paciente e tratá-lo emocionalmente e sintomaticamente, é fazer com que ele perceba o significado de sua enfermidade.

Já o Psico-Oncologista, diante de seu paciente, pode perguntar-se: "O que se pode fazer com essa pessoa para se resgatar as suas potencialidades, mesmo nessa situação de gravidade extrema? Como favorecer o paciente hospitalizado de modo que ele reencontre um sentido para sua vida, mediante a peculiaridade de seu diagnóstico?” É a partir daí que a abordagem gestáltica pode auxiliá-lo, orientando, conduzindo o terapeuta, uma vez que ela permite "tocar" o ser humano, a partir de um diálogo sensível, cuja pretensão é estar à disposição dos recursos que ainda não foram possíveis de se resgatar e assim não mais fragmentando o paciente em sua doença.

É importante avaliar a natureza e o grau de intensidade do acontecimento do adoecer na vida do indivíduo, e que recursos o paciente possui para um enfrentamento adequado da situação. Essa tarefa requer do terapeuta o uso total e imediato de suas habilidades, visto que não há tempo para esperar passivamente pelo insight ou pela 
elaboração, o que exige do psicólogo uma postura mais acolhedora e assertiva. Escutar não é tarefa fácil. Ouvir palavras repletas de dor, angústia ou sem nexo aparente, pode vir a ser um trabalho árduo.

Muitas vezes, atendendo o paciente, compreendendo seu sofrimento, vendo-o por inteiro, na sua totalidade, e não somente como uma doença, o terapeuta estará em sintonia com ele, saberá o que dizer e como agir, como "ajudá-lo a ajudar-se". Outras vezes, mesmo tendo essa postura, pouco se poderá fazer. É importante a consciência do que não depende do psicólogo e sim do paciente, pois depende do outro o que é do outro. Neste sentido, o terapeuta é colocado também frente às suas possibilidades e limites, tirando-o do lugar onipotente que muitas vezes busca estar.

Embora seja importante estudar e entender as causas do câncer, a Gestalt-terapia busca a sua funcionalidade, seu processo, a forma como a doença se expressa e como é significada pelo paciente. Essa concepção não valoriza o "por que" das coisas e sim o "como" e o "para que". Trata-se de um pensamento sistêmico, que aceita a interação de numerosos fatos e que vê o ser humano em toda sua plenitude e totalidade. É tão importante conhecer a pessoa que tema doença quanto conhecer a doença que a pessoa tem.

Enfim, estar disponível para traçar um caminho, ser presença no diálogo relacional com o paciente iluminando-o (e também sendo iluminado) é uma grande tarefa da terapia da Gestalt, e, com bastante empenho e criatividade, numa construção onde o paciente e terapeuta possam seguir um caminho possível, fazendo do adoecer uma experiência transformadora.

Fica aqui, como uma das alternativas de suporte e de mobilização de mecanismos de enfrentamento do indivíduo, o acompanhamento terapêutico à luz da Gestaltterapia, com a sua compreensão de homem e de seu adoecimento, que privilegia a integração das partes, até então vistas como fragmentadas. Para essa abordagem, a patologia realmente precisa ser explorada, especialmente o câncer, porém dentro de um contexto: como um processo que, no momento presente, vem bloquear a expressão e percepção do indivíduo em sua forma mais produtiva. E é por isso que se faz necessária uma ampliação nas maneiras de enxergar e abarcar o adoecer, na medida em que é fundamental ao próprio sujeito adoecido buscar um sentido para sua vida, uma forma de reconfigurar a sua essência e a sua existência.

\section{Referências}

Alvim, M. B. (2006). Contato e cultura organizacional: Ensaio para um modelo Psicológico de análise organizacional na perspectiva da abordagem gestáltica. Dissertação de Mestrado em Psicologia, Universidade de Brasília, Brasília.
Antony, S. M. \& Ribeiro, J.P. (2005). Hiperatividade: doença ou essência um enfoque da gestalt-terapia. Psicologia, Ciência e Profissão, 25(2): 186-197.

Barbalho, M.C.M. (1998). Saúde e doença na Gestalt-terapia uma questão de contato. Revista do IV Encontro Goiano da Abordagem Gestáltica. 4: 71-76.

Bottura, W. (2007). Psiconeuroimunologia. Rev Med (São Paulo), jan-mar, 86(1): 01-05

Brandão, L. M. (2003). Psicologia hospitalar: uma abordagem holística e fenomenológico-existencial. Campinas: Livro Pleno.

Frazão, L. M. (1999). A compreensão do funcionamento saudável e não saudável a serviço do pensamento diagnóstico em Gestalt-Terapia. Revista do VEncontro Goiano da Abordagem Gestáltica, 5, p. 27-34.

Forghieri, Y. C. (2004). Psicologia Fenomenológica: fundamentos, método e pesquisa. São Paulo: Thomson Learning.

Fukumitsu, K. O. (2009). O cuidado na saúde e na doença: uma perspectiva gestáltica. Estudos e Pesquisas em Psicologia (UERJ). 9(1), 174-194.

Garcia, M. A. A, Tafuri, M. J, Nogueira, R. C., \& Carcinoni, T.M. (2000). A Depressão em pacientes cm câncer: uma revisão. Revista de Ciências Médicas de Campinas, 9(2):80-85.

Gimenes, M. G. G. (2003). Definição, foco de estudo e intervenção. Em: M. M. M. J. Carvalho (Org.), Introdução à psiconcologia (pp. 36-56). São Paulo: Livro Pleno.

Holland, J. C. \& Lewis S. (2000). The human side of cancer: living with hope, coping with uncertainty. New York: Quill.

Hycner, R. (1995). De pessoa a pessoa: psicoterapia dialógica. São Paulo: Summus.

Imes, S. A.; Clance, P. R.; Galies, A. T. \& Atkeson, F. (2002). Mind's response to the body's betrayal: Gestalt/Existential therapy for clients with chronic or life-threatening illnesses. Journal of Clinical Psychology, 58(11): 1361-1373.

Ivancko, S. M. (2006). Uma compreensão psicossomática do órgão de choque através do trabalho com polaridades. Dissertação de Mestrado, Pontifícia Universidade Católica de São Paulo, São Paulo.

Kiyan, A. M. M. (2006). E a Gestalt emerge: vida e obra de Frederick Perls. São Paulo: Altana.

Liberato, R. P., \& Carvalho, V.A. (2008). Psicoterapia. Em V. A. Carvalho; M. H. P. Franco, M. J. Kovács, R. C. Macieira, M. T. Veit, M. J. B. Gomes, P. Liberato \& L. Holtz (Eds.), Temas em psico-oncologia (pp. 341-350). São Paulo: Summus.

Martín, A. (2008). Manual prático de psicoterapia gestalt. Petrópolis: Vozes.

Ministério da Saúde (2010a). Instituto Nacional do Câncer. O que é câncer. Disponível em <http://www.inca.gov.br/conteudo_view.asp?id=322>.

Ministério da Saúde (2010b) Instituto Nacional do Câncer. O que causa o câncer. Disponível em <http://www.inca.gov. br/conteudo view.asp?id=81>. 
Peçanha, D. L. N. (2008). Câncer: recursos de enfrentamento na trajetória da doença. Em V. A. Carvalho, M. H. P. Franco, M. J. Kovács, R. C. Macieira, M. T. Veit, M. J. B. Gomes, P. Liberato \& L. Holtz (Eds), Temas em psico-oncologia (pp. 209-217). São Paulo: Summus.

Perls, F. S. (1977). Gestalt-terapia explicada (2ª ed.). São Paulo: Summus.

Perls, F. S. (1988). A abordagem gestáltica e testemunha ocular da terapia. Rio de Janeiro: LTC.

Perls, F. S., Hefferline, H., \& Goodman, P. (1997). Gestalt-terapia. São Paulo: Summus.

Polster, E., \& Polster, M. (2001). Gestalt-terapia integrada. São Paulo: Summus.

Remen, R. N. (1993). O paciente como ser humano. São Paulo: Summus.

Ribeiro, J. P. \& Alvim, M. B. (1997). Saúde e doença nas organizações. Revista do III Encontro Goiano da Abordagem Gestáltica, 3, 32-38.

Ribeiro, J. P. (1999). Gestalt-terapia de curta duração. São Paulo: Summus.

Ribeiro, J. P. (2007). O ciclo do contato: temas básicos na abordagem gestáltica. São Paulo: Summus.

Rodrigues, H. E. (2000). Introdução a Gestalt-Terapia. Petrópolis: Vozes.

Rossi, L. (2007). Psicologia e emergências médicas. Em J. Quayle \& S. Lucia (Orgs.), Adoecer: as interações do doente com sua doença I (pp. 169-187). São Paulo: Atheneu.

Schillings, A. (1997). Mutilações e mutações: trajetória de um trabalho com pacientes com câncer na abordagem gestáltica. Revista do III Encontro Goiano da Abordagem Gestáltica. 3, 23-31.
Sontag, S. (2007). Doença como metáfora, AIDS e suas metáforas. São Paulo: Companhia das Letras.

[WHO] World Health Organization (2010). Mental health: a state of well-being. Disponível em <http://www.who.int/ features/factfiles/mental_health/en/>.

[WHO] World Health Organization.(2010). The impact of cancer in Brazil. Disponível em <http://www.who.int/infobase/report.aspx?rid=119\&iso=BRA\&generateReport $=$ Gene rate+Report>

Yontef, G. M. (1998). Processo, diálogo e awareness. São Paulo: Summus.

Younes, R. N. (2001). O câncer. São Paulo: Publifolha.

Rafaella Brito e Silva - Psicóloga Clínica, Psico-Oncologista pela Sociedade Brasileira de Psico-Oncologia (SBPO), Especialista em Psicologia Hospitalar com ênfase em Oncologia pelo Hospital do Câncer A.C. Camargo de São Paulo, Especialista em Psicologia Clínica pelo Instituto de Gestalt-Terapia de Brasília (IGTB). Mestranda em Psicologia Clínica pela Pontifícia Universidade Católica de São Paulo. Email: rafa_brito@yahoo.com.br

Carolina Brum Faria Boaventura - Psicóloga Clínica, Especialista e Mestre em Psicologia Clínica pela Universidade Católica de Brasília. Professora e Orientadora do Curso de Especialização do Instituto de Gestalt-Terapia de Brasília (IGTB). Professora da Universidade Paulista (UNIP). Endereço Institucional: SBN, Qd. 02, Bl. J, Lj. 1 (Térreo) - Ed. Eng. Paulo Maurício - Brasília-DF. Email: carolbrum@hotmail.com

Recebido em 28.01.11 Primeira Decisão Editorial em 15.05.11 Segunda Decisão Editorial em 29.07.11 Aceito em 15.08.11 